\title{
LÍMITES CONSTITUCIONALES A LA INSERCIÓN DE TASAS JUDICIALES AUTONÓMICAS. COMENTARIO CRÍTICO A LA STC 71/2014, DE 6 DE MAYO
}

\author{
Eduardo Sánchez Álvarez
}

doi: 10.18543/ed-64(1)-2016pp377-394

\begin{abstract}
SUMARIO: 1. InTRODUCCIÓN. 2. REGULACIÓN NORMATIVA. 2.1. Las posibilidades competenciales autonómicas en el ámbito de la justicia. 2.2. Tasas judiciales autonómicas. 2.2.1. Mención al concepto de la tasa. 2.2.2. Su proyección al ámbito de la justicia. 2.2.3. La Ley 5/2012, de 20 de marzo, de la Comunidad de Cataluña. 3. LA STC 71/2014, DE 6 DE MAYO. EXPOSICIÓN Y CRÍTICA. 3.1. Argumentación del Tribunal Constitucional. 3.1.1. Aspecto competencial. 3.1.2. No existencia de doble imposición. 3.1.3. Diferencias entre la tasa estatal y la autonómica. 3.2. Voto particular. 3.2.1. Doble imposición. 3.2.2. Desigualdad en el ejercicio de un derecho fundamental. 3.3. Postura subjetiva. 3.3.1. El concepto administración de la Administración de Justicia y sus consecuencias. 3.3.2. Hechos imponibles.
\end{abstract}

\section{INTRODUCCIÓN}

La Ley 10/2012, de 20 de noviembre, por la que se regulan determinadas tasas en el ámbito de la Administración de Justicia y del Instituto Nacional de Toxicología y Ciencias Forenses (ltj, en lo sucesivo) ha suscitado un generalizado debate doctrinal y popular, así como una contestación unánime por parte de los operadores jurídicos.

Las tasas judiciales no son un fenómeno desconocido a lo largo de los últimos tiempos en nuestro Ordenamiento jurídico -desde su reintroducción por la Ley 53/2002, de 30 de diciembre- y cuentan con precedentes históri- 
cos en época preconstitucional. Sin embargo, la expansividad de la regulación implementada, tanto en lo objetivo (hitos y momentos procesales que quedan gravados y convertidos en hechos imponibles de la tasa) como en lo subjetivo (los sujetos pasivos de la tasa no se reducen a personas jurídicas con un alto volumen de facturación económica, pese a ulteriores dulcificaciones introducidas por medio del art. 11 del Decreto-Ley 1/2015, de 28 de febrero), no ha amedrentado al legislador a la hora de poner en vigor la nueva presentación de esta figura tributaria.

El legislador se justifica en la oportunidad y conveniencia de que el ciudadano pueda pagar por los servicios que recibe de la Administración de Justicia $^{1}$. Se proclama la necesidad de implantar un modelo de Justicia en el cual se realce la viabilidad de que parte de su coste sea soportado por quienes más se beneficien de él, pretendiéndose con ello una racionalización en el ejercicio de la potestad jurisdiccional a la par que recaudar cantidades que permitirán acometer mejor los gastos que inevitablemente van unidos al funcionamiento de la maquinaria judicial del Estado.

Los ahogos presupuestarios no solamente afectan a la Administración General del Estado. Se extienden igualmente, si no con mayor intensidad, a las Comunidades autónomas españolas. Gran parte de ellas ostentan competencias engarzables a lo que supone la Administración de Justicia entendida en un sentido laxo. Por ello, se plantea el supuesto relativo a si estas entida-

${ }^{1}$ «La existencia de la tasa judicial encuentra óbice en las previsiones constitucionales sobre la gratuidad de la Justicia» (LOREDo COLUNGA, M: «Las tasas judiciales: una controvertida alternativa de financiación de la Justicia», Indret, Barcelona, 2005, p. 6). A contrario sensu, como se señala en la medular STC 20/2012, de 16 de febrero, cierto es que relativa a las tasas introducidas por el art. 35 de la Ley 53/2002, de 30 de diciembre, de Medidas fiscales, administrativas y de orden social, tremendamente más restrictivas y puntuales que las ahora relanzadas y puestas en vigor, «en principio no vulnera la Constitución que una norma de rango legal someta a entidades mercantiles, con un elevado volumen de facturación, al pago de unas tasas que sirven para financiar los costes generados por la actividad jurisdiccional que conlleva juzgar las demandas que libremente deciden presentar ante los Tribunales del orden civil para defender sus derechos e intereses legítimos. Esta conclusión general sólo podría verse modificada si se demostrase que la cuantía de las tasas establecidas (...) son tan elevadas que impiden en la práctica el acceso a la Jurisdicción o lo obstaculizan en un caso concreto en términos irrazonables» (FF. JJ. 9. ${ }^{\circ}$ y $10 .^{\circ}$ ), lo que seguramente supone la vía abierta al cuestionamiento de la regulación presente de esta figura tributaria. En cualquier caso, esa Sentencia no reprocha al legislador que pida al justiciable mediante la exacción de tasas su colaboración o contribución al sostenimiento de los gastos generados con la actividad del aparato jurisdiccional del Estado instado por aquél, pues «es lícito que el legislador adopte medidas para lograr un alto grado espontáneo de la obligación de pagar un tributo legítimo, aun cuando esas medidas incidan en el ejercicio del derecho de acceso a la Jurisdicción» (FJ 11. $\left.{ }^{\circ}\right)$. 
des también tienen capacidad de establecer sus propias y agregadas tasas en estos terrenos sobre los que ejercitan sus potestades.

Por tanto, se trata de analizar cuál es el nivel competencial autonómico en el ámbito de la Justicia para, en su caso, habilitar la instauración de tasas sobre el mismo. Ello, además, sin incurrir en supuestos de doble imposición y evitando interferencias en el indisponible ejercicio de un derecho fundamental a su vez con contenido complejo, el de tutela judicial efectiva consagrado por el art. 24.1 de la Constitución (CE).

\section{REGULACIÓN NORMATIVA}

En primer término, se propone referir el conjunto de elementos jurídiconormativos que inciden sobre la cuestión planteada.

\subsection{Las posibilidades competenciales autonómicas en el ámbito de la justicia}

La opción constitucional de Poder Judicial que en su momento se eligió quedó basada en el principio de unidad jurisdiccional (art. 117.5 CE), al margen de que orgánicamente ese Poder se presente en la práctica como descentralizado, multicéntrico y capilarmente ramificado por todo el territorio estatal ${ }^{2}$.

Sin embargo, el proceso estatuyente y sus ulteriores reformas ampliatorias de los sucesivos techos competenciales instaurados invalidaron esa consideración. Los Estatutos de autonomía procedieron a exteriorizar la voluntad de estas entidades de ejercitar potestades en el ámbito de la Administración de Justicia, con los límites que se precisaran posteriormente, mediante la introducción en el articulado estatutario de las que se han denominado cláusulas subrogatorias. La redacción de esas normas estatutarias vendría a ser bastante similar en todos los casos en los que se positivizaban, en el sentido de indicar que la Comunidad de turno ejercería las facultades que las Leyes Orgánicas del Poder Judicial (LOPJ) y de su Consejo General reconocieran o

${ }^{2}$ «Nuestro modelo constitucional se basa en un Poder Judicial alejado de realidades federales, otorgando un papel preeminente a la legislación estatal» (TORRES MURO, I. y Álvarez Rodríguez, I: «El Poder Judicial en Cataluña en la STC 31/2010, de 28 de junio», Teoría y Realidad Constitucional, UNED, Madrid, 2011, p. 346). «Por ello carecen (...) de sentido constitucional las continuas apelaciones (...) a una necesaria adaptación autonómica del Poder Judicial. El Poder Judicial constitucional fue pensado por los constituyentes bajo un molde unitario con una estructura jerarquizada de órganos judiciales estatales» (VÍRgala ForURIA, E: «El Poder Judicial en las Comunidades autónomas», en «Poder Judicial y unidad jurisdiccional en el Estado autonómico», CGPJ, Madrid, 2006, p. 405). 
atribuyeran al Gobierno del Estado en relación con la Administración de Justicia. En suma, lo que las Normas estatutarias sentaban era una remisión a la LOPJ.

La única forma de salvar esa aparente contradicción entre el Texto constitucional y la voluntad normativizada en los Estatutos de autonomía que no pasara por una aplicación literal del principio de jerarquía constitucional inactivando las cláusulas subrogatorias, exigía la estimación de la necesidad de formular una disociación en el tenor del art. 149.1.5. ${ }^{\circ} \mathrm{CE}$ consistente en escindir un concepto estricto de Administración de Justicia y otro amplio, de tal modo que en el primero no cupiera que las Comunidades Autónomas pudieran tener ninguna intervención mientras en el segundo sí. Así procedió el Tribunal Constitucional (TC), instaurando una jurídicamente vinculante línea doctrinal muy estable de la que suponen ejemplos claros, entre otras, las Sentencias 56/1990, de 29 de marzo; 62/1990, de 30 de marzo; 158/1992, de 26 de octubre; 105/2000, de 13 de abril; 294/2006, de 11 de octubre o $31 / 2010$, de 28 de junio.

Se gestó la diferencia entre Administración de Justicia en sentido restringido y administración de la Administración de Justicia ${ }^{3}$, sin lesionar o desnaturalizar el principio constitucional de unidad orgánica y funcional del Poder Judicial ${ }^{4}$. En el ámbito conceptual de la administración de la Administración de Justicia situado fuera del núcleo duro de la Administración de Justicia, identificada con la previsión del art. 149.1.5. ${ }^{\circ} \mathrm{CE}$, las Comunidades autónomas podrían ejercitar competencias, siempre con el matiz de que desarrollen esos poderes en los límites marcados por las cláusulas subrogatorias, esto es, en los ámbitos que la LOPJ reserva al Gobierno.

${ }^{3}$ «A la vista del proceso de aprobación de los Estatutos de Autonomía y de la propia Constitución, puede afirmarse que la distinción entre un sentido amplio y un sentido estricto en el concepto de Administración de Justicia no es algo irrelevante jurídicamente. Esa diferencia presente en toda la organización y regulación de la función jurisdiccional (...) tiene, al menos, valor para distinguir entre función jurisdiccional propiamente dicha y ordenación de los elementos intrínsecamente unidos a la determinación de la independencia con que debe desarrollarse por un lado, y otros aspectos que, más o menos unidos a lo anterior, le sirven de sustento material o personal, por otro (...) No se cuestiona la unidad material de la Administración de Justicia del art. 149.1.5. ; lo que se cuestiona es si la llamada administración de la Administración de Justicia se integra o no en el citado precepto o si, por el contrario, se trata de otra materia independiente y, por tanto, situada fuera del ámbito de la Administración de Justicia» (STC 56/1990, de 29 de marzo, FJ 7.º).

${ }_{4}$ «Unidad orgánica y funcional del Poder Judicial que se asegura en su sustancia con la atribución al Estado de la competencia exclusiva en materia de Administración de Justicia, la cual es perfectamente compatible con el reconocimiento a las Comunidades autónomas de determinadas competencias propias de la vertiente puramente administrativa al servicio de la función jurisdiccional del Estado (STC 31/2010, de 28 de junio, FJ 42 in fine)»-STC 162/2012, de 20 de setiembre, FJ 5. ${ }^{\circ}-$. 
Se concluye que el Poder Judicial es único, ya que «una de las características definidoras del Estado autonómico, por contraste con el federal, es que su diversidad funcional y orgánica no alcanza en ningún caso a la Jurisdicción» (STC 31/2010, de 28 de junio, FJ 42. ${ }^{\circ}$ ). Pero, frente a «ese núcleo esencial de lo que debe entenderse por Administración de Justicia existe un conjunto de medios personales y materiales que, ciertamente, no se integran en ese núcleo, sino que se coloca, como dice expresamente el art. 122.1 CE al referirse al personal, al servicio de la Administración de Justicia, esto es, no estrictamente integrados en ella. En cuanto no resultan elemento esencial de la función jurisdiccional y del autogobierno del Poder Judicial, cabe aceptar que las Comunidades autónomas asuman competencias sobre esos medios personales y materiales» (STC 162/2012, de 20 de setiembre, FJ 5. ${ }^{\circ}$ ). En síntesis, definiendo a la expresión administración de la Administración de Justicia hacemos mención a la vertiente puramente administrativa al servicio de la privativa función jurisdiccional del Estado, sin perjuicio de las dificultades prácticas esperables para el trazo de contornos nítidos de diferenciación en todo supuesto posible planteable (infra).

Así es, en esa vertiente aparentemente administrativa se enraízan funciones, desarrolladas por personal al servicio de la Administración de Justicia traspasable a la gestión autonómica, que son imprescindibles para el correcto ejercicio de la potestad jurisdiccional tal cual la contempla el art. 117.3 CE y que se concretan en la realización de actos procesales, plenamente fundidos con la función jurisdiccional propia del Estado en el margen cubierto por el art. 149.1.5. ${ }^{\circ} \mathrm{CE}$ (sin más, arts. 475 a), 476, 477 o 478 LOPJ). En concreto, dentro de esa idea o concepto «administración de la Administración de Justicia», los campos sobre los que las potestades autonómicas van a poder proyectarse son principalmente dos: el personal no jurisdicente y los medios materiales precisos para el recto desenvolvimiento de la actividad jurisdiccional.

\subsection{Tasas judiciales autonómicas}

Procederemos ahora a analizar el encaje de las tasas judiciales y su eventual implantación por las Comunidades autónomas, tanto en una óptica genérica cuanto sobre un supuesto real concreto.

\subsubsection{Mención al concepto de la tasa}

Como es bien sabido, la tasa constituye una de las modalidades posibles de tributo. El art. 6 de la Ley 58/2003, de 17 de diciembre, General Tributaria -LGT- define a las tasas como el tributo cuyo hecho imponible consiste en la utilización privativa o el aprovechamiento especial del dominio público, la 
prestación de servicios o la realización de actividades en régimen de Derecho público que se refieran, afecten o beneficien de modo particular al obligado tributario, cuando los servicios o actividades no sean de solicitud o recepción voluntaria para los obligados tributarios o no se presten o realicen por el sector privado.

Estas modalidades tributarias se basan en el principio de equivalencia aunque no puedan desconocer la capacidad económica del sujeto pasivo de la misma, de forma que su hecho imponible «encierra un sinalagma (...) que consiste en la utilización privativa o el aprovechamiento especial del dominio público, la prestación de servicios o la realización de actividades en régimen de Derecho público que se refieran, afecten o beneficien de modo particular al obligado tributario» -STC 296/1994, de 10 de noviembre, FJ 2. ${ }^{\circ}$.

Por tanto, elemento esencial del hecho imponible de la tasa es su ligazón a una actividad o servicio de la Administración Pública. Consiguientemente, la determinación del sujeto pasivo se hace por referencia a la actividad administrativa; y el importe de su cuota ha de fijarse principalmente atendiendo al coste de esa actividad o servicio prestado, a modo de contraprestación.

\subsubsection{Su proyección al ámbito de la justicia}

Del art. 1 LTJ se desprende que estas tasas tienen carácter estatal, siendo exigibles por igual en todo su territorio cuando se produzcan los hechos imponibles legalmente erigidos por el art. 2 LTJ. Ahora bien, queda expresamente a salvo la posibilidad de su concurrencia con otras tasas o tributos que puedan exigir las Comunidades autónomas en el ejercicio de sus respectivas competencias financieras, con la única excepción consistente en que «no podrán gravar los mismos hechos imponibles», esto es, no siendo factible incurrir en doble imposición (art. 1 in fine LTJ, infra).

Se habilita la permisividad de las tasas autonómicas en sus espectros competenciales propios conexos a la Justicia con esas dos limitaciones: ceñirse a su ámbito de capacidades y no incurrir en doble imposición, es decir, no poder pautar como hechos imponibles los que ya elija para este fin el Estado. En nuestra opinión, este segundo límite es redundante, pues el tenor del art. 6.2 de la Ley Orgánica 8/1980, de Financiación de las Comunidades autónomas (LOFCA, en adelante), instaura que «los tributos que establezcan las Comunidades autónomas no podrán recaer sobre hechos imponibles gravados por el Estado» ${ }^{5}$.

${ }^{5}$ Los límites contenidos en la LOFCA «reflejan que la competencia autonómica para establecer tributos ex novo no se configura constitucionalmente en términos absolutos, sino que se encuentra sujeta a los límites establecidos en las leyes del Estado a que se refieren los arts. 133.2 y 157.3 CE (...) El poder tributario de las Comunidades autóno- 
Entendemos que el ejercicio de la potestad jurisdiccional a la que se refiere genéricamente la LTJ como ámbito aplicativo de estos tributos no constituye per se el servicio público de la Justicia, habida cuenta que hay que contar con un concepto amplio en el que se integran elementos personales y materiales que le sirven de sustento a la mismísima función jurisdiccional los cuales, caso de haberse efectuado traspaso competencial, son aportados por las Comunidades autónomas. Pero ello no permite un poder ilimitado de estas Corporaciones a la hora de implantar tasas que graven a este sector.

Acudiendo a la doctrina del TC sobre este particular, es cierto que «la competencia para crear tasas por servicios deriva necesariamente de la que se ostenta para crear las instituciones y organizar los servicios públicos correspondientes» (STC 204/2002, de 31 de octubre, FJ 3. ${ }^{\circ}$ ), lo que conlleva que la capacidad para la creación y regulación de esos tributos queda vinculada a la existencia de la competencia material. Pues bien, en lo que al objeto de estudio atañe, la función jurisdiccional stricto sensu junto a la ordenación de los elementos intrínsecamente ligados a la independencia con la cual debe desarrollarse (art. 117.1 CE), lleva al TC a concluir que esta cuestión ha de incardinarse a la competencia exclusiva estatal referida por el art. 149.1.5. ${ }^{\circ}$ $\mathrm{CE}$, es decir, a la Administración de Justicia en sentido restringido (STC 162/2012, de 20 de septiembre, FJ 5. ${ }^{\circ}$, supra).

La creación de tasas por las Comunidades autónomas se vincula necesariamente a su competencia material. «La tasa sigue al servicio», de tal forma que «la distribución de competencias en una materia determina la posibilidad de establecer tasas sobre la misma, así como su configuración», art. 7.1 LOFCA (STC 136/2012, de 19 de junio, FJ 8. ${ }^{\circ}$ ).

Entonces, el primer tope infranqueable que comentábamos antes se ve respaldado por el TC considerando que la configuración de la tasa judicial reglada en la LTJ excluye que nos hallemos en la faz administrativa apegada a la función jurisdiccional del Estado, ya que nos encontramos con hechos imponibles constituidos por determinados actos procesales que, lógicamente, se hallan regulados por la legislación procesal (ergo estatal, reténgase) y «ante órganos que son expresión de un Poder único en todo el territorio del Estado» (nuevamente, STC 162/2012, de 20 de setiembre, FJ 5. ${ }^{\circ}$ ). Las tasas judiciales implementadas de esta forma «son tributos cuyo hecho imponible no es ajeno a la función jurisdiccional-campo vedado a las competencias autonómicas, supra- y que imponen una carga económica que persigue un

mas puede asi ser delimitado por el Estado, salvaguardando en todo caso su propia existencia de manera que no se produzca un vaciamiento de la competencia, pues (...) ninguno de los límites constitucionales que condicionan dicho poder (...) puede ser interpretado de tal manera que haga inviable el ejercicio de aquella potestad tributaria» (STC 201/2012, de 14 de noviembre, FJ 4. ${ }^{\circ}$ ). 
fin vinculado al proceso mismo -igualmente ajeno al hecho autonómico visto que enhebra instrumentalmente al derecho fundamental a la tutela judicial efectiva»-(STC 20/2012, de 16 de febrero, FJ 12. ${ }^{\circ}$ ).

Así, los hechos imponibles radicalmente procesales que contempla el art. 2 LTJ no son susceptibles de ser escogidos por las Comunidades autónomas con competencias asumidas en materia de administración de la Administración de Justicia. Esos hechos imponibles no recaen sobre el servicio público de la Justicia apto para ser ejercitado en parte por esas Corporaciones (gestionándolo en lo que concierne a la dotación y financiación de los medios humanos y materiales oportunos), sino sobre la indeclinable actividad estatal que constituye el ejercicio de la potestad jurisdiccional. «La consecuencia es que el hecho imponible de la tasa está desvinculado de las competencias autonómicas relativas a la previsión de los medios materiales necesarios para el desarrollo de la función judicial y, por tanto, corresponde al Estado la competencia para establecerla así como su gestión y recaudación», lo cual trae como corolario que «no puede aceptarse aquí la invocación de la competencia autonómica (...) pues solamente en el sentido amplio de la noción de Administración de Justicia tienen cabida las competencias autonómicas y (...) nos encontramos aqui en el ámbito estricto de la Administración de Justicia» (STC 162/2012, de 20 de setiembre, FJ cit.).

Bien, practicada toda esta acotación material, ¿qué hechos imponibles son susceptibles de ser gravados por tasas autonómicas sin rebasar esos límites instaurados?

\subsubsection{La Ley $5 / 2012$, de 20 de marzo, de la Comunidad de Cataluña}

La Norma a la que acudir es la Ley 5/2012, de 20 de marzo, de la Comunidad de Cataluña, de Medidas Fiscales, Financieras y Administrativas y de Creación del Impuesto sobre las Estancias en Establecimientos Turísticos (BOE de 6 de abril de 2012), la cual instaura una tasa autonómica para el justiciable y otra tasa para la utilización o el aprovechamiento de los bienes y derechos afectos al servicio de la Administración de Justicia. El extenso tenor del art. 3 bis 1-1 de la Norma desmenuza los hechos imponibles elegidos ${ }^{6}$.

${ }^{6}$ «Constituye el hecho imponible de la tasa la prestación de servicios personales y materiales en el ámbito de la administración de la Administración de Justicia de competencia de la Generalidad (nótese), a instancia de parte, en los órdenes jurisdiccionales civil y contencioso-administrativo, en los órganos judiciales con sede en Cataluña. La producción del hecho imponible se manifiesta mediante la realización de los siguientes actos:

a) En el orden jurisdiccional civil, con independencia de la cuantía: la interposición de la demanda de juicio ordinario, la formulación de reconvención en el juicio ordinario y la presentación de la solicitud de declaración de concurso. 


\section{LA STC 71/2014, DE 6 DE MAYO. EXPOSICIÓN Y CRÍTICA}

Procedamos ahora a detenernos en el análisis de la STC 71/2014, de 6 de mayo.

\subsection{Argumentación del Tribunal Constitucional}

Suscitado recurso de inconstitucionalidad contra la Norma referida de la Comunidad autónoma catalana, el TC zanja la cuestión mediante esa Sentencia, concluyendo la constitucionalidad de la tasa creada por la Generalidad en el ámbito de la Justicia. Los argumentos que abocan a esta determinación pueden estructurarse de la siguiente manera.

\subsubsection{Aspecto competencial}

El primer jalón del problema a despejar estriba en si la Comunidad autónoma catalana tiene competencia para estatuir esta tasa.

Ha quedado expuesto que, una vez disociada dentro del concepto Administración de Justicia una óptica estricta a retener por el Estado de otra más laxa que significa aquel plantel de competencias típicas de la vertiente administrativa al servicio de la función jurisdiccional del Estado que no se adentra en su núcleo constitucionalmente indelegable, ésta ha sido susceptible de ser traspasada a las Comunidades autónomas (STC 31/2010, de 28 de junio, cit.). Consiguientemente, diferenciadas ambas laderas y ostentadas de iure por las entidades autonómicas capacidades de diversa índole y profundidad sobre medios personales y materiales al servicio de la Administración de Justicia, para el TC «es posible

b) En el orden jurisdiccional civil, en los casos de cuantía superior a 3.000 euros: la interposición de demanda de juicio verbal, la formulación de reconvención en el juicio verbal, la interposición de demanda de procesos de ejecución de títulos extrajudiciales, la interposición de demanda de juicio cambiario y la presentación de la petición inicial del procedimiento monitorio y del proceso monitorio europeo.

c) En el orden jurisdiccional civil, en los casos de cuantía superior a 6.000 euros: la interposición de la demanda en los procesos de ejecución de títulos judiciales.

d) La interposición de recursos de apelación, extraordinario por infracción procesal $y$ de casación en el orden civil.

e) La interposición de recurso contencioso-administrativo de cuantía superior a 3.000 euros.

f) La interposición de recursos de apelación y casación en el ámbito de la jurisdicción contencioso-administrativa.

A los efectos de lo establecido por la presente ley, los procedimientos de cuantía indeterminada o aquéllos en los que sea imposible efectuar su determinación de acuerdo con las normas de la Ley de Enjuiciamiento Civil, se consideran de cuantía superior a 6.000 euros». 
la imposición de tasas autonómicas sobre dicha administración de la Administración de Justicia (...) Sentado que en las tasas la competencia para su creación y regulación se encuentra estrechamente ligada a la competencia material» (FJ 4. ${ }^{\circ}$ ). El TC concluye la compatibilidad de ambas esferas y, por tanto, la concurrencia de tasas sobre ellas al constituir realidades escindibles.

La tasa estatal por el ejercicio de la potestad jurisdiccional queda encuadrada en el sentido riguroso apegado al art. 149.1.5. ${ }^{\circ} \mathrm{CE}$ : «se vincula directamente con el acceso a la Jurisdicción civil o contencioso-administrativa, así como con la continuación de procesos judiciales ya iniciados en esos órdenes jurisdiccionales, y persigue financiar los costes generados por la actividad jurisdiccional que conlleva juzgar las demandas que determinados justiciables deciden libremente interponer en defensa de sus derechos e intereses legítimos, disminuyendo así correlativamente la financiación procedente de los impuestos con cargo a la generalidad de los ciudadanos» (FJ 4 de nuevo). Por lo tanto, la regulación de la tasa estatal selecciona como hecho imponible el ejercicio mismo de la potestad jurisdiccional y no el servicio público de la Administración de Justicia, asignable a las capacidades gestoras de las Comunidades autónomas. La tasa estatal se ciñe al ámbito propio e intransferible del Poder Judicial a reservar al Estado, luego plenamente desvinculado de las competencias autonómicas relativas a la provisión de medios precisos para el recto desarrollo de la función jurisdiccional: «estaba vinculada al ejercicio de la actividad jurisdiccional (...) compatible con el establecimiento de tasas judiciales en el ámbito estatutariamente permitido».

A contrario sensu, el TC entiende que existe la facultad autonómica de implantar tasas sobre su competencia propia, es decir, la administración de la Administración de Justicia, sin que decaiga el brocardo «la tasa sigue al servicio». Este tributo afecta a una dimensión distinta que el estatal, no incide en la función jurisdiccional sobre la que las autonomías adolecen de cualquier competencia: «al disponer la Comunidad autónoma de Cataluña de la obligada competencia material, puede instaurar una tasa que financie su ejercicio (...) Y así lo confirma además expresamente el art. 1 de la (...) Ley estatal 10/2012, al reconocer que la tasa por el ejercicio de la potestad jurisdiccional se aplicará sin perjuicio de las tasas y demás tributos que puedan exigir las Comunidades autónomas en el ejercicio de sus respectivas competencias financieras, los cuales no podrán gravar los mismos hechos imponibles. No cabe por tanto cuestionar la constitucionalidad de un hecho imponible que coincide con el reparto de competencias en la materia» (FJ 5. ${ }^{\circ}$ ).

\subsubsection{No existencia de doble imposición}

Debe analizarse qué hechos imponibles se seleccionan en concreto para este tributo. Más arriba hemos hecho transcripción de ellos y, si se comparan 
con los fijados por el art. 2 LTJ, no puede negarse la más que evidente cercanía cuando no aparente identidad entre ellos. En ese caso, nos hallaríamos ante un supuesto de doble imposición que, de inmediato, abortaría el vigor del tenor del art. 6.2 LOFCA.

El TC procede a salvar esta eventualidad razonando que «es cierto que (...) la tasa autonómica se debe (...) con ocasión del inicio de los procesos allí definidos. Sin embargo, la redacción (...) no permite alcanzar conclusiones precipitadas (...) En este supuesto (...) tal inexcusable operación interpretativa debe partir de la premisa de que la proximidad parcial entre hechos imponibles deriva de la propia cercanía de las competencias». Aunque conceptualmente la dualidad Administración de Justicia (función jurisdiccional; Estado)-administración de la Administración de Justicia (respaldo a la función jurisdiccional sin entrar en su recinto, simplemente a su servicio; Comunidades autónomas) no parezca engendrar mayores dificultades, la praxis denota una proximidad que tal vez eclipse el trazo de unas precisas líneas fronterizas. Para el TC «es pues incuestionable que los actos procesales generan también un coste administrativo. Y asimismo innegable que el coste de dicha competencia administrativa se justifica por y para la competencia propiamente jurisdiccional, hasta el punto que sin el ejercicio de esta última no existe la primera -reténgase-. En otras palabras, los servicios administrativos constituyen precisamente un apoyo de la potestad jurisdiccional, que a su vez se erige en su prius lógico. Por tanto, el coste de dichos servicios administrativos está directamente asociado al número de asuntos que franquean su entrada en los órganos jurisdiccionales».

La dispar configuración de los respectivos hechos imponibles no puede relegar la íntima vinculación entre los dos ámbitos competenciales en concurrencia, estatal y autonómico, razón por la cual «el mero dato de que la tasa se defina o conecte en el aspecto temporal de su devengo con determinadas actuaciones procesales no puede determinar automáticamente que la competencia estatal quede afectada» (FJ 5. ${ }^{\circ}$, nuevamente).

\subsubsection{Diferencias entre la tasa estatal y la autonómica}

Entre ambas tasas, aun convergentes en tantos aspectos, el TC también entresaca alguna diferencia con notables repercusiones. «A diferencia de lo que sucede con la tasa del Estado, la autonómica no está enlazada con el acceso a la Jurisdicción o a los recursos, ya que el pago de la misma no constituye condición de admisibilidad de los actos procesales cuya vertiente administrativa pretende financiar. Mientras que la conexión de las tasas estatales con la potestad jurisdiccional es directa y resulta patente (...) siendo así conditio sine qua non para el propio ejercicio de la tutela judicial efectiva, el abono de la tasa autonómica carece, como no puede ser constitucio- 
nalmente de otro modo, de toda consecuencia impeditiva o retardaria del acceso a la Jurisdicción» (FJ 5. ${ }^{\circ}$ ).

El TC reconoce la armonía de ambas tasas adoptando como único prisma de enjuiciamiento el establecimiento de la autonómica dentro del marco competencial que corresponde a la Generalidad. «Sólo puede descartarse totalmente la coincidencia entre ambas tasas siempre que se interprete que el segundo inciso del art. 3 bis 1-1 (...) se refiere en realidad al devengo de la tasa autonómica, cuyo hecho imponible es la actividad administrativa inherente a la competencia definida como administración de la Administración de Justicia, que incluye todos los elementos que sirven de sustento a la propia función jurisdiccional (...) en los términos asumidos mediante» el Estatuto de autonomía catalán (FJ 6. ${ }^{\circ}$ ). A juicio del TC, la configuración del hecho imponible y el devengo de la tasa en juego resultan compatibles con la financiación de los medios personales y materiales, competencia autonómica que se pretende sufragar de esa manera. «Se evidencia así que la tasa autonómica constituye el exacto reverso de la tasa estatal», recayendo la primera sobre la administración de la Administración de Justicia y la segunda sobre la potestad jurisdiccional indeclinablemente estatal.

Bajo ese enfoque exegético, el TC estima que esta tasa no es contraria a la CE.

\subsection{Voto particular}

La STC 71/2014, de 6 de mayo, cuenta con un voto particular. Las ideas en que se fundamenta pueden ser sistematizadas como sigue:

\subsubsection{Doble imposición}

Contra el criterio mayoritario adoptado por el Pleno del TC, la opinión discrepante indica que la entrada en vigor de la tasa autonómica en cuestión hace repercutir sobre el ciudadano la doble imposición de un mismo hecho imponible, pues «la respuesta a la actuación jurisdiccional que genera el ciudadano recurrente está constituida, de modo simultáneo e inescindible, por tareas de contenido procesal y realización de funciones administrativas vinculadas a las anteriores», por lo que se niega la quirúrgica distinción mantenida en el FJ 5. ${ }^{\circ}$ entre la tasa estatal ligada al acceso a la Jurisdicción o los recursos y la autonómica ceñida a sufragar los gastos generados por el aparato auxiliar a la función jurisdiccional. Lo determinante es que el justiciable que aspira a ejercer su derecho fundamental a una tutela judicial efectiva «ha de pagar por partida doble para verlo satisfecho».

La situación verdaderamente subyacente es que «la distribución de competencias, obligada en un Estado compuesto, no debe razonablemente abo- 
car al pago por partida doble del servicio público instrumentado al respecto (...) La Administración de Justicia funciona a solicitud del sujeto pasivo, siendo su interposición de la demanda y la solicitud del servicio inescindibles». La tasa autonómica grava actos procesales, luego jurisdiccionales $\mathrm{y}$ estatales, y no meras actuaciones administrativas, ergo no se limita a los supuestos que le parecerían connaturalmente propios, ajustados a actividades estrictamente administrativas, desagregadas del desarrollo del proceso ( $v . g r$. petición de copias o certificaciones). Al contrario, esta tasa entra de lleno en lo procesal.

\subsubsection{Desigualdad en el ejercicio de un derecho fundamental}

Corolario inevitable de este diseño de la tasa autonómica analizada, resulta ser que se produce una tangible situación de desigualdad en el acceso a la tutela judicial efectiva de los ciudadanos de una determinada Comunidad autónoma en parangón con los de las restantes. Así, un derecho fundamental se dispensará de manera dispar, como mínimo en lo que a costes se refiere, en función de la parte del Estado en que el ciudadano litigue impetrando justicia.

\subsection{Postura subjetiva}

A nuestro entender, la decisión que contiene la Sentencia comentada no es especialmente afortunada y tendemos a acercarnos más a la argumentación de su voto particular. Se sustenta esa conclusión sobre dos ejes fundamentales.

\subsubsection{El concepto administración de la Administración de Justicia y sus consecuencias}

Ha de asumirse que la doctrina constitucional ha introducido, asentado y perfilado la existencia del concepto administración de la Administración de Justicia. Ahora bien, es tangible que la mera existencia de tal concepto encierra en sí un grado de sensible artificiosidad que no se va a circunscribir a lo meramente académico. El caso que se analiza es ejemplo suficiente de la concurrencia de esta eventualidad.

Estimamos que no es posible desplegar la función jurisdiccional sin asociarle la labor, tanto administrativa como procesalmente auxiliar, que le aporta el entramado denominado administración de la Administración de Justicia, quien erige un Poder Judicial instrumental. Dentro de este engranaje, en perspectiva orgánica, resulta totalmente contingente que determinados extremos se puedan confiar a las Comunidades autónomas bajo el imperio 
del principio de oportunidad, sin que quepa que impliquen congelación competencial definitiva a favor de aquellas dado que no se integran en los textos estatutarios, sino que simplemente se transfieren en virtud de una cláusula formalmente estatutaria que reenvía, a su vez, a lo que la LOPJ prevea.

Conviene inclinarse por una consideración integral del Poder Judicial que comprenda todos los elementos que, de una manera u otra, lo forman, con independencia de las funciones o responsabilidades, hondamente interrelacionadas entre sí (criterios de procesalidad o jurisdiccionalidad) que despliegue cada uno de los miembros de ese organismo que conforma in toto el Poder en liza. Lo medular se halla en que tal unidad corpórea precisa de todos sus miembros en perfecta sintonía para cumplir la integridad de sus responsabilidades, siempre orientadas al ejercicio de la estatal función jurisdiccional.

Son perfectamente legítimas las aspiraciones de cada individuo administrativo comprometido en la participación gestora del sistema judicial. Pero interaccionan con otros bienes que, constitucionalmente, se presentan en unos niveles de prevalencia muy superiores. Está en juego el correcto funcionamiento del Estado de Derecho, el angular derecho fundamental a la tutela judicial realmente efectiva que bajo ningún concepto habrá de sufrir por discusiones competenciales o deficiencias de gestión gubernativa de la parte del Poder Judicial que supone su faz instrumental ${ }^{7}$, a la par que con sus miras puestas en un palmario interés general que ha de colocar en un plano totalmente irrelevante a este tipo de aspectos caso de pugna. No tiene por qué resultar lesivo a las Comunidades autónomas el mantenimiento, por volición constitucional, de un Poder del Estado que se presente organizado sobre el principio de unidad, acarreando capacidades muy limitadas a ejercitar por aquellas sobre este.

La conclusión que se alcanza es que las distonías dimanantes de la inserción del concepto administración de la Administración de Justicia basamentada principalmente en respetar intereses gubernativos, exige la implementación de medidas recaudatorias de ámbito autonómico, en aras de cubrir los

${ }^{7}$ «El lógico y razonable entendimiento de la independencia del Poder Judicial obliga a interpretar y exigir que la prestación de servicios personales y materiales por parte de la administración de la Administración de Justicia no traspase ese límite ni se erija, por tanto, en propia Administración de Justicia. Eso sería contar con un poder compartido donde quiebra el principio de separación de poderes, de forma que el Poder Judicial se ve condicionado y reducido a niveles que dificilmente le permitirán desarrollar la alta misión constitucionalmente encomendada que no es sólo la de juzgar y ejecutar lo juzgado, sino ser garante de una tutela efectiva en la defensa de los derechos dentro de un Estado social y democrático de Derecho que, por definición, implica contar con una mayor independencia del Poder Judicial» (DEL Río FERNÁNDEZ, L: «Independencia judicial y separación de poderes», Diario La Ley, n. ${ }^{\circ}$ 6838, de 11 de diciembre de 2007). 
gastos generados por la asunción de esa parte instrumental del Poder Judicial. La creación de una categoría jurídica, ciertamente forzada a nuestro entender, acaba trasladándose al justiciable con unos costes mayores por ejercer un derecho fundamental, máxime cuando el mismo Estado también grava su reducto competencial, el ejercicio de la potestad jurisdiccional. La escisión de dos partes que más bien erigen un todo interrelacionado e interdependiente acaba ocasionando un pago doble, un repago.

Lógicamente, desde un enfoque eminente y aisladamente competencial, nada puede oponerse a su creación: si las Comunidades autónomas prestan los servicios correspondientes a la administración de la Administración de Justicia, podrán crear estas tasas. Otra cosa es analizar qué se esconde tras esa categoría jurídica que habilita gravar con tasas al justiciable, o valorar si verdaderamente el academicismo del concepto objeto de análisis debería diluirlo en su sede natural, la potestad jurisdiccional, abortando ipso facto que pudiera ser germen de tasas autónomas desagregadas de su tronco.

\subsubsection{Hechos imponibles}

Aun partiendo de la existencia del concepto administración de la Administración de Justicia y de la competencia y responsabilidad autonómica sobre el mismo, habilitando de iure la inserción de potenciales tasas que lo graven en legítimo ejercicio de sus poderes en este ámbito, no dejan de gestarse problemas a la hora de seleccionar su hecho imponible, en especial teniendo en cuenta la absoluta imposibilidad de su elección si previamente el Estado ya los ha adoptado.

El contenido jurídico encadenable a la idea administración de la Administración de Justicia comprende los medios materiales y humanos al servicio y apoyo de la función jurisdiccional no integrados en el núcleo duro de ésta. Justamente ese espectro vago, amplio y difuso dificulta qué se puede pautar como hecho imponible de una tasa que grave al Poder Judicial instrumental: ¿papel utilizado, copias, tinta, tiempo de los funcionarios que tramiten los procedimientos judiciales? ¿No forma parte todo ese elenco de la función jurisdiccional, dado que sin ellos no puede llevarse a cabo (el papel que requiera una sentencia, el funcionario que la transcriba o la inserte en el sistema informático de gestión procesal, etc.)?

La Norma catalana evita estos problemas a cambio de precipitarse de lleno en la prohibida doble imposición. De los hechos imponibles que selecciona se desprende tajantemente que se han elegido los que en realidad son dominio del Estado. Todos ellos son actos procesales, siendo el proceso conducción instrumental que vertebra y encauza la función jurisdiccional y el ejercicio del derecho fundamental a la tutela judicial efectiva. En consecuencia, no es factible que sean objeto de erigir hecho imponible de una tasa au- 
tonómica, sobre todo una vez el Estado los ha reclutado en la LTJ con una expansividad casi integral. No es que la tasa autonómica constituya el reverso de la estatal. A nuestro juicio es exactamente la misma, como lo son sus hechos imponibles, al margen de las diferencias de matiz en orden a coartar o no la prosecución procesal que su impago pueda acarrear, desde el instante en que lo procesal es absolutamente ajeno al hecho autonómico, por ser apero de la función jurisdiccional.

En atención a la naturaleza de las labores que realizan los funcionarios nominalmente adscritos a la administración de la Administración de Justicia, radicalmente procesales $\mathrm{y}$, si son administrativas, fusionadas inescindiblemente con aquéllas, los hechos imponibles seleccionados no son aptos de serlo por una Comunidad autónoma. Y argumento análogo puede predicarse en relación a los medios materiales. Esta tasa autonómica lesiona al derecho fundamental del art. 24.1 CE y su error de diseño es evidente, dejando aparte el irrelevante aspecto, visto el daño infligido, de dejar a salvo un pretendido equilibrio en lo que al reparto competencial Estado-Comunidad autónoma atañe. La tasa judicial del Estado es discutible por si $^{8}$, pero la autonómica tal cual se ha presentado es inadmisible.

A mayor abundamiento, el art. 149.1.6. ${ }^{\circ} \mathrm{CE}$ proclama como competencia exclusiva estatal la legislación procesal, abrigando la necesidad de la salvaguarda de la uniformidad de los instrumentos jurisdiccionales en todo el territorio nacional (cfr. STC 83/1986, de 26 de junio). Diríamos que lo procesal, con alguna pequeña salvedad constitucionalmente afirmada - «sin perjuicio de las necesarias especialidades que en este orden se deriven de las particularidades del Derecho sustantivo de las Comunidades autónomas»-,

${ }^{8}$ Se argumenta en la STSJ de Cataluña, Sala de lo Contencioso-administrativo, de 30 de enero de 2014 (referencia índice CENDOJ 08019330032014100043), que «una cosa es el supuesto de hecho que se prevé en materia tributaria y otra cosa las consecuencias procesales que se pretenden derivar, que ponen en riesgo el mismo derecho fundamental a la tutela judicial efectiva (...) que (...) determina la imposibilidad de que el impago total o parcial de cualquier tasa pueda impedir por sí solo el acceso del interesado a aquella tutela a través de la promoción del correspondiente proceso o recurso, o al trámite y resolución de cualesquiera escritos presentados en su seno, siempre sin perjuicio de que la falta de presentación de la correspondiente autoliquidación, siendo exigible, pudiera ser comunicada, a los efectos procedentes, al organismo administrativo encargado de la gestión de la indicada tasa (...) Existe (...) una falta de proporcionalidad entre el objetivo que se persigue -la recaudación-y el modo en que se opera (...) se establece una medida que (...) interfiere en el ejercicio del derecho fundamental, obstaculizando el derecho a la acción que forma parte del contenido esencial del mismo y (...) que desnaturaliza el ejercicio de la función jurisdiccional, haciendo tomar parte activa al órgano judicial en la gestión de la obligación tributaria pendiente y atribuyendo a dicha gestión un carácter preferente (...) obstáculo reduplicado (...) con la conclusión de resultar inconstitucional la limitación de los derechos reconocidos en el artículo 24 de la Constitución Española». 
no encaja con las competencias autonómicas debido a su ligazón a la tutela judicial efectiva y la función jurisdiccional. Por tanto, tampoco parece viable que las Comunidades autónomas puedan gravar tributariamente este terreno.

La STC 71/2014, de 6 de mayo, no ha entrado a fondo en el asunto, conformándose con dar un visto bueno sobre un análisis centrado mayoritariamente en el reparto competencial entre el Estado y la Comunidad autónoma. A nuestro entender, el derecho fundamental a la tutela judicial efectiva ha de primar sin lugar a dudas sobre ese detalle puramente administrativo, trayendo como colofón la inadmisión e inconstitucionalidad de la tasa autonómica arbitrada: la Administración autonómica tiene una competencia formal sobre cuyo ámbito puede instaurar tasa; pero como es difícil -cuando no imposible con la cirugía precisa, por desmembrar jirones de un todo ontológico- fijar asépticamente sus hechos imponibles, ha seleccionado un elenco de ellos sobre los que materialmente ya no es competente.

Se ha obviado que el núcleo de la cuestión anida en que esa determinación incide tanto sobre la legislación procesal exclusiva competencia estatal (art. 149.1.6. ${ }^{\circ} \mathrm{CE}$ ) cuanto, lo que es cualitativamente más intenso, obstaculiza decisiva y notablemente al derecho fundamental a la tutela judicial efectiva que se sirve del proceso para su encauzamiento y dispensación.

En opinión particular, y con base en los razonamientos antedichos, se estima que debería haberse declarado la inconstitucionalidad de esa medida tributaria autonómica.

TITLE: Constitutional limits to the establishment of autonomic court fees. Review of Judgment 71/2014 of the Spanish Constitutional Court

RESUMEN: La polémica apegada a las tasas judiciales también tiene otras derivadas como la relativa a que alguna Comunidad autónoma con competencias asumidas en esa materia haya decidido crear sus propias tasas sobre ese sector. El Tribunal Constitucional ya ha tenido ocasión de practicar un pronunciamiento sobre el asunto aunque, en nuestra opinión, aún orbitan sobre la cuestión dudas jurídicas que su decisión no zanja. En este trabajo se propone un estudio de esa cuestión junto al análisis crítico de la referida STC 71/2014, de 6 de mayo, que contiene ese parecer del Tribunal Constitucional. Su inevitable cohonestación con el derecho fundamental a la tutela judicial efectiva, junto a un enfoque más administrativo o competencial, serán los criterios rectores de esa reflexión.

Palabras Clave: tasa, Constitución, justicia, derecho.

ABSTRACT: The judicial taxes also takes other matters as their creation by autonomous Communities with faculties assumed in this area. The Spanish Constitutional Court already has had occasion to practise a pro- 
nouncement on the question though, in our opinion, still float on this trouble, and whose his decision maybe does not tackle. In the following pages, we propose a study of this situation close to the critical analysis of the STC 71/2014, of May 6, which it contains this to seem of the Spanish Constitutional Court.

KEY WORDS: tax, Constitution, justicia, right.

RECIBIDO: 21.01.2016

ACEPTADO: 22.06 .2016 